\title{
Accuracy and Reproducibility of Quantitative Coronary Arteriography Using 6 and 8 French Catheters with Cine Angiographic Acquisition
}

\author{
Stephen G. Ellis, MD, Ibraim M.F. Pinto, MD, Mark J. McGillem, BS, Scott F. DeBoe, BS, \\ Michael T. LeFree, and G.B. John Mancini, MD
}

\begin{abstract}
To determine the suitability of 6 French catheters for quantitative coronary arteriography, the relative accuracy and reproducibility of one type of these catheters was compared to that obtained with standard 8 French catheters in 20 stenoses. Duplicate injections with polyurethane 6 French catheters were obtained using hand and power injection technique with cineangiographic acquisition (four 6 French catheter injections total per stenosis). Measurements of both percent diameter stenosis and absolute dimensions were compared to those obtained with hand injection and cine acquisition using 8 French catheters as a "gold standard." While the reproducibility of dimension determination with the 6 French catheter was generally similar to that obtained with the 8 French catheter $(0.27 \pm 0.23 \mathrm{~mm}$ for absolute diameter and $8.1 \pm 7.4 \%$ for percent diameter stenosis), accuracy was significantly less for the 6 French catheter for measurement of absolute dimensions. Thus, while apparently well suited for serial measurements of the same stenoses, 6 French catheters may not be as accurate in the determination of absolute artery dimensions as 8 French catheters.
\end{abstract}

Key words: quantitative arteriography, angiography

\section{INTRODUCTION}

Assessment of coronary artery dimensions has been found to have physiologic and prognostic importance in several clinical settings [1-4]. In fact, it has been suggested that change in dimensions be an appropriate surrogate endpoint for clinical events in studies such as interventions on coronary artery disease progression so as to decrease the substantial cost of such trials [5].

The usual manner of clinical assessment of coronary disease severity, visual estimation of percent stenosis from coronary arteriograms obtained during hospitalization, is neither accurate nor precise [6,7], thus leading to the development of quantitative computer techniques to assess disease severity $[8-10]$. The cost of such procedures could be minimized by the use of outpatient catheterization. However, the accuracy and reproducibility of coronary angiography obtained using 5 French catheters has been questioned [11-14], and that of 6 French catheters that might also facilitate outpatient catheterization is not known. If such catheters could be utilized, the cost of intervention trials could be decreased and the number of patients who are willing to participate might be increased.

\section{PATIENTS AND METHODS \\ Study Population}

Fifteen patients without renal disease (serum creatinine $<2.0 \mathrm{mg}$ ) or resting ischemia referred for diagnostic coronary arteriography comprised the study population. All patients were selected prior to knowledge of coronary anatomy and no patients were rejected from the study once they had given informed consent. All patients were studied with standard cine angiophic techniques using 8 French catheters (Cordis Corp., Miami, FL) with hand injection technique immediately prior to the study. All stenoses estimated to reduce normal vessel diameter by $\geq 20 \%$ that were well visualized without foreshortening

From the Division of Cardiology, Department of Internal Medicine, University of Michigan Hospital and Veterans Administration Medical Center, University of Michigan Medical School, Ann Arbor, Michigan.

Received February 6, 1990; revision accepted August 6, 1990

Address reprint requests to Stephen G. Ellis, M.D., F.A.C.C., University Michigan Medical Center, Room B1 F245, 1500 E. Medical Center Drive, Ann Arbor, MI 48109-0022. 
or branch vessel overlap and a single best projection were then selected by the investigator (G.B.J.M. or S.G.E.) for study evaluation.

\section{Radiographic Technique}

All arteriography was performed with commercially available radiographic units (Siemens BiCor Pandoros 1200A, Erlangen, West Germany; Philips Optimus M100, Eindhoven, The Netherlands). The radiographic tubes used a 1.0 and $0.6 \mathrm{~mm}$ nominal focal spot. Coronary imaging was performed using a $17 \mathrm{~cm}$ field of view at 30 frames per second. Five to $10 \mathrm{ml}$ of Renografin 76 (E.R. Squibb \& Sons, Princeton, NJ) was injected manually by an experienced angiographer, or using a Medrad Mark IV power injector (Pittsburgh, PA) set to deliver $6-8 \mathrm{ml}$ at $5 \mathrm{ml} / \mathrm{sec}$ with a $0.5 \mathrm{sec} \mathrm{ramp}$ for the left coronary artery system and $4-6 \mathrm{ml}$ at $3 \mathrm{ml} / \mathrm{sec}$ with a 0.5 sec ramp for the right coronary artery. Automatic brightness control by the $\mathrm{X}$-ray generators adjusted the tube potential from 70 to $100 \mathrm{kV}$ and the pulse width between 2 and $10 \mathrm{msec}$. The nominal $X$-ray exposure at the image intensifier input was 25 microRoentgen per frame.

Each stenosis was sequentially imaged using the 8 French catheter (internal diameter $=.056$ in.) and hand injection technique onto cine film, and the 6 French catheter (polyurethane construction, internal diameter = .048 in., American Edwards Laboratories, Irvine, CA) with hand or power injections onto cine film in random order and following intracoronary instillation of $250 \mu \mathrm{g}$ nitroglycerin.

Collimation and imaging technique were optimized by the angiographer, but was unchanged for each study injection. Care was taken to ensure that both the stenosis and the angiographic catheter were within the central portion of the radiographic field to minimize the possible effects of pincushion distortion. Each injection was performed in duplicate.

\section{Cineangiogram Technique}

Cineangiograms were obtained on conventional 35 mm film (Kodak CFR, Rochester, NY). Processing was performed according to manufacturer's specifications and quality control standards.

\section{Image Interpretation}

Cine images were examined and processed by a single observer. For analysis, optimal images were projected on a Vanguard cine projector (Model XR-35, Melville, NY) which was optically coupled to a video camera. Using 2.4:1 optical magnification, the resulting video signal corresponding to a subregion of the $35 \mathrm{~mm}$ frame was digitized at $512 \times 512 \times 8$ bit resolution onto angiographic computer system. The video noise of this method of digitization was reduced by averaging 25 video frames prior to storage of each image.

All images were analyzed using a previously described and validated automatic coronary quantitation program [10]. A calibration factor was obtained by imaging and measuring the catheter.

\section{Statistical Analysis}

Results are expressed as mean \pm 1 standard deviation, unless otherwise indicated.

Reproducibility (mean of absolute differences between measurements) was assessed by comparison of the first and second injections with each technique, with the first injection serving as a "gold-standard." Statistical analysis was performed using paired Student's $t$-tests.

Relative accuracy (regression slope and mean difference between measurements) was determined by comparison of the results with the first of two injections using the 6 French catheter with those from the second 8 French cine angiogram hand injection, using the first 8 French cine angiogram hand injection as the "gold-standard." Slopes and standard errors of the estimate for each comparison were determined and tested for statistically significant differences between injection techniques using linear regression models wherein the 8 French data were added to the 6 French data to ascertain if they added significantly to the estimate of the "gold-standard."

\section{RESULTS}

There were 14 males and 1 female in the study population. The stenoses evaluated were located as follows: 3 proximal left anterior descending, 3 mid-distal left anterior descending, 2 proximal circumflex, 3 distal circumflex, 5 proximal right coronary artery, and 4 middistal right coronary artery. The mean stenosis diameter $=1.64 \pm 0.83 \mathrm{~mm}$ and the percent diameter stenosis using an adjacent "normal" arterial segment as reference $=53.9 \pm 18.7 \%$. Catheter instability (tendency to recoil from the ostium) was noted in 4/60 6 French injections and 0/30 8 French injections, $p=$ NS. Clinically important contrast streaming was observed in 6/60 6 French injections and $1 / 308$ French injections ( $p=$ NS). The results for reproducibility are shown in Table I and for relative accuracy in Table II and Figure 1.

\section{DISCUSSION}

Accurate and reproducible quantitative coronary angiography has been achieved using 8 French catheter sys- 
TABLE I. Reproducibility of Repeated Measurements

\begin{tabular}{lccc}
\hline \multicolumn{4}{c}{ Absolute Diameter $(n=20)$} \\
\hline Catheter & Injection & $\begin{array}{c}\text { Absolute differences } \\
\text { between repeated } \\
\text { measurements }(\mathrm{mm})\end{array}$ & $p$ value \\
\hline 8 French & Hand & $.27 \pm .23$ & - \\
6 French & Power & $.33 \pm .28$ & NS \\
6 French & Hand & $.30 \pm .21$ & NS \\
& Percent Stenosis $(n=20)$ & \\
& \multicolumn{4}{c}{ Absolute difference } \\
Catheter & Injection & between repeated & \\
\hline 8 French & Hand & & \\
6 French & Power & $8.1 \pm 7.4$ & $p$ value \\
6 French & Hand & $5.5 \pm 5.1$ & NS \\
\hline
\end{tabular}

TABLE II. Relative Accuracy of Measurements ${ }^{*}$

\begin{tabular}{lccccccc}
\hline \multicolumn{7}{c}{ Absolute Diameter $(n=20)$} & \\
\hline Catheter & Injection & Slope & Constant & SEE $(\mathrm{mm})$ & $R$ & $p$ value $^{\mathrm{a}}$ \\
\hline 8 French & Hand $^{\mathrm{b}}$ & .87 & .11 & .33 & .92 & - \\
6 French & Power & .84 & .23 & .38 & .90 & 0.06 \\
6 French & Hand & .80 & .24 & .38 & .89 & 0.05
\end{tabular}

$\%$ Diameter Stenosis $(n=20)$

\begin{tabular}{lcccccc}
\hline Catheter & Injection & Slope & Constant & (\% diameter) & $R$ & $p$ value $^{\mathrm{a}}$ \\
\hline 8 French & Hand $^{\mathrm{b}}$ & .78 & 12.2 & 10.4 & .84 & - \\
6 French & Power & .79 & 10.6 & 10.3 & .84 & NS \\
6 French & Hand & .90 & 6.1 & 8.1 & .91 & NS \\
\hline
\end{tabular}

*First 8 French hand injection used as "gold standard."

"For additional information supplied by second 8 French injection to first $6 \mathrm{Fr}$ injection as an estimate of dimensions assessed by first $8 \mathrm{Fr}$ injection.

${ }^{b}$ Second 8 French hand injection used as reference.

tems and with strict attention to the details of central catheter and stenosis placement in the field of view, avoidance of vessel foreshortening, and proper injection technique, as well as the technical concerns of pincushion distortion and $\mathrm{X}$-ray beam divergence [15]. The variability of repeated measurements has been reported to be as low as $\pm 3 \%$ for percent diameter stenosis and \pm 0.1 $\mathrm{mm}$ for minimal lesion diameter $[16,17]$. If similar results could be obtained with smaller 5 or 6 French catheters, patient acceptance of the follow-up catheterization required for coronary artery disease intervention studies could be optimized. Limited data suggest that this may not be possible with 5 French catheters [11-14].

In this study, 20 mild to moderately severe stenoses from 15 patients enrolled prospectively were sequentially interrogated using standard 8 French catheter techniques and 6 French catheters using hand and power injection, and cine acquisition. Statistically nonsignificant trends in catheter stability and contrast streaming were noted in favor of the 8 French catheters. Duplicate injections using standard 8 French catheter technique yielded variabilities of $.27 \pm .23 \mathrm{~mm}$ for absolute stenosis diameter and $8.1 \pm 7.4 \%$ in the measurement of diameter stenosis. For the 6 French catheter these values with hand and power injection were $.30 \pm .21 \mathrm{~mm}, .33 \pm .28 \mathrm{~mm}$, and $5.5 \pm 5.0 \%, 8.5 \pm 7.1 \%$, respectively. There was no difference between the reproducibility of 6 French catheter techniques and 8 French catheter techniques. For the parameter of relative accuracy, however, while the results with 6 French catheter techniques were equivalent to 8 French catheter techniques for the measurement of percent diameter stenosis (standard error of the estimate 8.1 to $10.3 \% r=.84-.91$ ), there was a definite trend for lessened accuracy with the 6 French catheters when absolute stenosis diameter was measured $[.38 \mathrm{~mm}$ and $r=$ $.89-.90 \mathrm{vs} .33 \mathrm{~mm}$ and $r=.92$ for 8 French catheters $(p=0.05$ and $=0.06 \%$ for hand and power injections, respectively)].

The relative inaccuracy of measuring absolute dimensions contrasts with apparent accuracy measuring percent diameter stenosis and suggests that a possible difficulty with the use of these catheters lies in the somewhat inexact or variable measurement of their diameter as a point of reference rather than their inability to allow adequate vessel contrast opacification for the technique evaluated. The general positive constants in regression equations relating absolute dimensional results of 6 to 8 French catheter measurements suggest that this may have resulted from a systematic overestimation of the catheter dimension by the computer edge tracking system. This difficulty may vary with catheter composition [18]. This study is limited by the relatively small number of stenoses interrogated, and in that generalization to results with catheters of different internal dimensions, composition, or with different methods of digital analysis cannot be presumed. However, catheters of polyurethane construction such as those tested have been shown to have measured size, image contrast, and average brightness gradient along the edges of the catheter equal to or superior to those of woven dacron, polyvinylchloride, or nylon composition [18].

Based upon these results, we would conclude that accurate measurement of percent diameter stenosis using these high flow 6 French catheters is possible, but that perhaps due to their relative lack of radiolucency compared to 8 French catheters, their use to measure absolute dimensions of stenoses may be questioned. However, since reproducibility with these 6 French catheters was not inferior to that with 8 French catheters, the use of the smaller catheters in serial studies appears justified. Improvements in catheter design that would allow better edge detection of the external dimensions of the catheter 

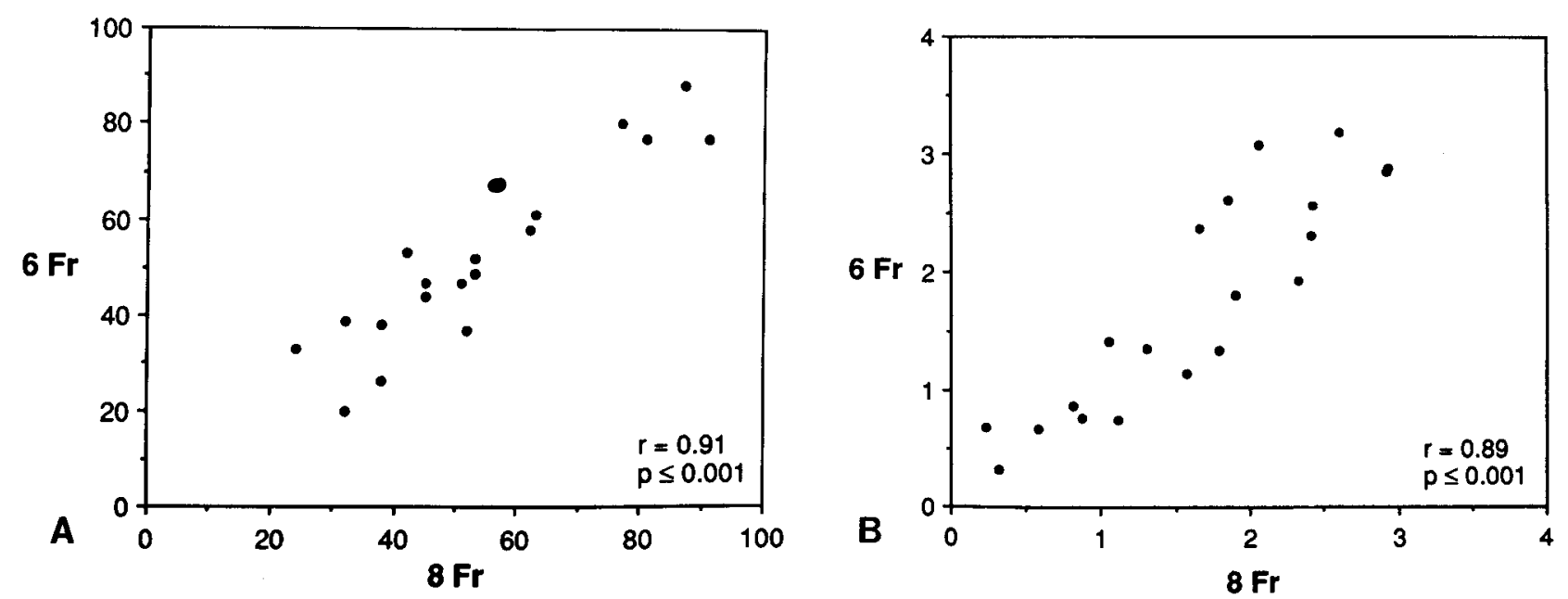

Fig. 1. Comparison of measurements of percent diameter stenosis (A) and of absolute stenosis dimension (B) using 8 and 6 French catheters and hand injection technique.

without compromise of luminal flow would be desirable. These results may have important implications for patient follow-up in studies investigating coronary artery disease treatment.

\section{ACKNOWLEDGMENTS}

Partial funding for this study was obtained by means of an educational grant from the American Edwards Laboratories, Irvine, CA.

\section{REFERENCES}

1. Harrison DG, White CW, Hiratzka LF, et al.: The value of lesion cross-sectional area determined by quantitative coronary angiography in assessing the physiologic significance of proximal left anterior descending coronary arterial stenoses. Circulation 69: 1111-1119, 1984.

2. Serruys PW, Wijns W, Van Den Brand M, et al.: Is transluminal coronary angioplasty mandatory after successful thrombolysis? Quantitative coronary angiographic study. Br Heart J 50:257265, 1983.

3. Harrison DG, Furguson DW, Collins SM, et al.: Rethrombosis after reperfusion with streptokinase: Importance of geometry of residual lesions. Circulation 69:991-999, 1984.

4. Serruys PW, Luijten KJ, Geuskens R: Incidence of restenosis after successful coronary angioplasty: A time-related phenomenon. Circulation 77:361-371, 1988.

5. Ellis S, Sanders W, Goulet C, et al.: Optimal detection of the progression of coronary artery disease: Comparison of methods suitable for risk factor intervention trials. Circulation 74:12351242, 1986.

6. Zir LM, Miller SW, Dinsmore RE, Gilbert JP, Harthorne JW: Interobserver variability in coronary angiography. $\mathrm{N}$ Engl $\mathbf{J}$ Med 53:627-632, 1976.

7. DeRouen TA, Murray JA, Owen W: Variability in the analysis of coronary arteriograms. Circulation 55:324-328, 1977

8. Brown BG, Bolson E, Frimer M, Dodge HT: Quantitative coro- nary arteriography: estimation of dimensions, hemodynamic resistance, and atheroma mass of coronary artery lesions using the arteriogram and digital computation. Circulation 55:329-337, 1977.

9. Rafflenbuel W, Smith LR, Rogers WJ, Mantle JA, Rackley CE, Russell RO: Quantitative coronary arteriography: Coronary anatomy of patients with unstable angina pectoris reexamined 1 year after optimal medical therapy. Am J Cardiol 43:699-707, 1979.

10. Mancini GBJ, Simon SB, McGillem MJ, LeFree MT, Friedman HZ, Vogel RA: Automated quantitative coronary arteriography: Morphologic and physiologic validation in vivo of a rapid digital angiographic method. Circulation 75:452-460, 1987.

11. Brown RIG, MacDonald AC: Use of 5 French catheters for cardiac catheterization and coronary angiography: a critical review. Cathet Cardiovasc Diag 13:214-217, 1987.

12. Molajo AO, Ward C, Bray CL, Dobson D: Comparison of the performance of superflow $(5 \mathrm{~F})$ and conventional $8 \mathrm{~F}$ catheter for cardiac catheterization by the femoral route. Cathet Cardiovasc Diag 13:275-276, 1987.

13. Klinke WP, Hui W, Kubac G, Talip T: Comparison of 5F and $7 / 8 \mathrm{~F}$ catheters for left heart catheterization and angiography. Clin Res 37:95A, 1989.

14. Ellis SG, DeBoe SF, Sanz ML, Mancini GBM: Accuracy (A) and reproducibility ( $R$ ) of $5 \mathrm{Fr}$ catheter systems for outpatient use compared with 8 Fr systems. Circulation 76:IV-369, 1987.

15. Brown BG, Bolson EL, Dodge HT: Arteriographic assessment of coronary atherosclerosis: Review of current methods, their limitations, and clinical applications. Arteriosclerosis 2:2-15, 1982.

16. Tobis J, Nalcioglu O, Iseri L, Johnston WD, Roeck W, Castleman E, Bauer B, Montelli S, Henry WL. Detection and quantitation of coronary artery stenoses from digital subtraction angiograms compared with 35-millimeter film cineangiograms. Am J Cardiol 54:489-496, 1984.

17. Reiber JHC, Serruys PW, Kooijman CJ, Kooijman CJ, Wijns W, Slager CJ, Gerbrands JJ, Schuurbiers JCH, Boer A, Hugenholtz PG: Assessment of short-, medium-, and long-term variations in arterial dimensions from computer-assisted quantitation of coronary cineangiograms. Circulation 71:280-288, 1985.

18. Reiber JHC, Kooijman CJ, denBoer A, Serruys PW: Assessment of dimensions and image quality of coronary contrast catheters from cineangiograms. Cathet Cardiovas Diag 11:521-531, 1985. 